\title{
Giotto steals a ride
}

\section{Munich}

THE Earth lost a minute fraction of its orbital velocity earlier this week as the European Space Agency (ESA) Giotto space probe stole a little of the Earth's energy to help it on its way to a rendezvous with the comet Grigg Skjellerup. It was the first time the manoeuvre, the same "gravity assist" that helped the NASA Voyager probe on its journey from Jupiter out to Saturn and Neptune, had been executed using the gravitation field of Earth. According to ESA researcher Trevor Morley, Giotto will gain $3.1 \mathrm{~km} / \mathrm{sec}$ in velocity, meaning that the Earth will slow in its orbit by one millimetre in every million centuries.

A free ride on the Earth's gravity was a welcome break for a project that is beset by funding uncertainties. Despite the tremendous success of the original Giotto mission to Comet Halley in 1986 (see Nature 320, 202 \& 321, 259; 1986) and the potential for further cometary exploration, ESA voted last month to make the Giotto Extended Mission (GEM) an optional, not mandatory, project within its science programme. Member states will meet in September to discuss whether they are prepared to pay for Giotto.

Project manager Manfred Grensemann at the ESA ground station in Darmstadt is "optimistic" that enough support can be found. He estimates that the next phase of the mission would cost 10 million ECU (about $\$ 8$ million), mostly for the communications needed to keep in touch with the probe as it moves farther away.

"Compared to starting a new mission, RHEUMATOID ARTHRITIS

\section{New institute for Berlin}

\section{Munich}

A RESTORED villa on the Kleiner Wannsee, a lake within West Berlin city limits, will become home for a new institute for research into the causes of rheumatoid arthritis. Immunologist Avrion Mitchison of University College, London, has been named as scientific director and will work in Berlin half-time.

As a result of a political squabble over the institute between the left-wing coalition of Social Democrats and Greens which took office last year in West Berlin and the Conservative Christian Democrats who begin the project, the institute will study not only the molecular biology of the disease but will also look at "psychosocial factors" that contribute to its development. Mitchison says that this area has been neglected in rheumatoid arthritis, especially in comparison to the attention it has received in cancer.

Steven Dickman this is a bargain", says GEM project scientist Gerhard Schwehm. Schwehm said that the second flyby would be a unique opportunity to expand knowledge of comets. It will be especially interesting, he said, to study the interaction of the coma of the comet and the solar wind, as well as to compare the distribution and optical properties of dust around Comet Grigg Skjellerup with that around Comet Halley, which had at least 100 times more of it.

Giotto was one of five spacecraft to approach Comet Halley in 1986, but it moved far closer than the others and came away with dazzling photographs of the nucleus. After the Halley encounter, Giotto was put into 'hibernation' to conserve power as researchers sought a suitable second comet to study with the craft. The probe will now be put into hibernation again until May 1992, when it will 'awaken' and prepare for the next encounter.

Unfortunately, said Grensemann, the camera that took the dramatic shots of the nucleus of Comet Halley is no longer operating - the sensors still function but no light reaches the aperture. But seven other instruments on board are at least partly operational and Grensemann expects them to deliver good data.

The researchers chose Comet Grigg Skjellerup as Giottos's target as much for practical as for scientific reasons. The comet was in a position in its orbit around the Sun that meant only minor adjustments in the trajectory of Giotto were needed for them to meet.

Steven Dickman

\section{CONFERENCES}

\section{Changes at Dahlem}

\section{Munich}

Silke Bernhard, scientific director of the Dahlem Conferences, is to step down because of ill health. A physician by training, Bernhard had been credited by participants with building the high international reputation of the conferences.

Last year, Bernhard struggled to maintain the conferences when their original backer, the 'Donors Association for Promoting Arts and Sciences in West Germany' (Stifterverband für die Deutsche Wissenschaft) withdrew its support. The Free University of Berlin took over sponsorship in November (see Nature 340, 86 \& 342, 466; 1989)

Jennifer Altman, a neuroscientist and formerly on the staff of Nature, will act as interim scientific director until an international search can be arranged for a permanent director.

Steven Dickman

\section{Murmurs of complaint}

\section{Washington}

JAPAN's national university professors are all employees of the government, which puts them in an odd position when they want to protest to the government about university conditions. But last month, the Association of National Universities finally succeeded, after years of trying, in winning funds from the Ministry of Education, Culture and Science to set up a committee to study their own financial difficulties.

The association represents all the 93 national universities directly supported by the government and has responsibility for setting up the general entrance examination.

Akito Arima, president of the association and of the University of Tokyo, recently described the universities' difficulties in a magazine of the Ministry of Finance. "In Japan about 1 per cent of GNP is allocated to college education and research, but in the United States it is $\mathbf{1 . 5}$ per cent. Within the limited budget, priority is placed much more on building new laboratories, moving universities, and big science, and less on the reconstruction or the maintenance of existing laboratories.

"As a result, buildings and equipment are becoming old and dilapidated. Good research cannot be produced by laboratories that are too small and lack both good equipment and money. We must find other financial sources." The new committee has not decided its plan of action and will first gather basic data.

Shigeko Segawa

\section{ANTARCTICA}

\section{Airstrip plans on ice}

\section{Sydney}

Australia has been forced to abandon plans to build an 'environmentally friendly' A \$1 million airstrip close to its Casey Base in Antarctica. The experimental runway was built on ice to minimize the effect on wildlife, most of which lives on the very small part of the Antarctic that is rock. Construction of a rock runway at the French Antarctic base led to an international outcry as Greenpeace claimed that an important breeding ground for Adélie penguins had been destroyed.

But ice has not proved to be safe after all, according to a report by the Royal Australian Air Force. Last summer, the report says, a vehicle broke through the ice on the runway and sank into the water beneath. Because of the risk of the runway melting and breaking up, the air force argues that a gravel airstrip should be built.

The Australian Department of the Environment's Antarctic Division has proposed an alternative site for an ice and snow runway $30 \mathrm{~km}$ away from Casey where the climate is harsher. The United States has a successful ice strip at its McMurdo base south of Casey. 